\title{
Real Risk-Free Rate, the Central Bank, and Stock Market Bubbles
}

\author{
Jukka llomäki and Hannu Laurila
}

This document has been downloaded from TamPub.uta.fi

The Insitutional Repository of University of Tampere

\begin{abstract}
Faculty of Management, Fl-33014 University of Tampere, Finland
Abstract: The central bank acts as a social planner, and adjusts the real risk-free rate of return to correct any mispricing in the stock market so that the emergence of positive or negative bubbles is avoided. The analysis shows that the central bank must raise the risk-free rate in the case of a positive bubble, and vice versa. Moreover, the central bank should intervene in the stock market even if it does not have perfect information about the bubble. This is because the sequential dividend yields in the pricing equations are stationary. Thus, even the delayed reaction of the central bank prevents the fundamental value and the equilibrium price from drifting apart for extended periods.
\end{abstract}

Keywords: Real Interest Rate, Monetary Policy, Portfolio Choice.

\section{INTRODUCTION}

What should be the role of the central banks in the context of stock market bubbles? For example, Bernanke and Gertler (2001), Greenspan (2004), and Posen (2006) argue that the central bank should concentrate on inflation targeting and stable growth, while Bordo \& Jeanne (2002), Bean (2004), and Roubini (2006) claim that the central bank should also tackle stock market bubbles. Yellen (2010) supports the latter view by stating that the central bank should intervene in stock market pricing, if the bubble gets dangerously large.

Viewing the question from another angle, Maio (2014) provides empirical support to "don't fight the Fed" -policy. He shows that the policy yields economically and statistically significant short-term gains comparing to buy-and-hold strategy. Obeying the "don't fight the Fed" principle means that investors should react by increasing/decreasing risky investments in the stock markets when the central bank reduces/raises the risk-free rate of return.

Furthermore, there are some practical examples of central banks' attacks on currency market bubbles by adjusting the risk-free rate. For example, the central bank of Russia reacted to its national currency market bubble in 2014 by raising the key interest rate (Gilenko 2017).

Concerning the means of intervention, Conlon (2015) suggest that the central bank should use its informational advantage, and intervene by warning the

*Address of correspondence to this author at the Faculty of Management, FI-33014 University of Tampere, Finland; Tel: +358401366117;

E-mail: jukka.ilomaki@uta.fi

JEL Classification: E43, E52, G11 investors about noticeable bubbles. Thus, inaction of the central bank implicitly means that the stock prices can rise. Furthermore, the intervention by the central bank may make things even worse if it does not have private information about the bubble. Fischer (2016) makes a stronger point by arguing that, in the case of economy-wide bubbles, the central bank should intervene by monetary policy.

A quite common perception about the proper cure for bubbles is the so called "leaning against the wind" type policy, which means that the risk-free rate must be lifted in order to de-inflate a positive bubble. However, there are confronting views, too. For example Gali (2014) claims that such a policy may actually make the bubble inflate even further. This may happen because the fundamental component of an asset price corresponds to the discounted stream of payoffs, but the bubble component has no payoffs to discount. Thus, the latter component grows at the rate of interest, at least in expectation.

Inspired by the above argumentations, we present a simple financial market model, where the central bank is in charge of the adjustment of stock market bubbles. The adjustment is achieved by controlling the market real return of risk-free assets via monetary policy. The maneuverability of bubbles is studied both with and without perfect information about efficient stock market pricing and thus about the existence of bubbles. The model yields a "leaning against the wind" type rule for monitoring and correcting any mispricing, and stabilizing the financial market.

The paper proceeds as follows. Section 2 presents related literature. Section 3 defines the basic model with informed and uninformed investors. Section 4 presents the analysis of the equilibrium in the financial 
market, and describes the interventions needed from the central bank to stabilize the financial market. Section 5 discusses the findings.

\section{LITERATURE REVIEW}

In our model, the key building block is the possibility of bubbles. The seminal efficiency argument by Samuelson (1973) is that, with perfectly rational riskneutral investors, the equilibrium stock price $\left(P_{t}\right)$ is equal to the expected discounted dividends to the shareholder, that is the fundamental value $\left(V_{t}\right)$. Tirole (1982) shows that $P_{t}=V_{t}$ holds also in the rational expectations equilibrium with long-lived risk averse investors so that infinite bubbles are impossible.

However, Tirole (1985) argues that, in an overlapping generations model with short lived investors and infinitely lived assets bubbles are possible so that $P_{t} \neq V_{t}$ may occasionally happen. Santos \& Woodford (1997) indicates that bubbles are impossible in rational markets only in the long run, but that there is a possibility of $P_{t} \neq V_{t}$ in the short run.

The overlapping generations model is here interpreted so that rational investors have a short-term investing horizon. For example Shleifer and Vishny (1997) argue that the short-lived-investor assumption can be motivated so that the majority of investors in the market are professional wealth managers who handle other people's money with performance monitoring in short intervals. Delong et al. (1990), Froot et al. (1992), Campbell and Kyle (1993), Kyle and Xiong (2001), Shiller (2014), and Ilomäki (2016) argue that, if there are informed and uninformed short-term (that is shortlived) investors in the market, $P_{t} \neq V_{t}$ exists because of the asymmetry and correlated behavior of the uniformed investors.

Furthermore, Allen et al. (2006), and Bacchetta \& Van Wincoop (2008) show that $P_{t} \neq V_{t}$ occurs in the case of short-lived investors, because their noisy private information incorporates rational higher-order beliefs into the equilibrium. Cespa \& Vives (2015) also uses a model of short-lived investors with asymmetric information, and ends to two extreme equilibriums: a high information equilibrium $P_{t}=V_{t}$ with low volatility and high liquidity, and a low information equilibrium $P_{t} \neq V_{t}$ with high volatility and low liquidity.

Therefore, our model builds on the assumption of asymmetric information among the investors, and on the argument of Loewenstein and Willard (2006) that the variation of the risk-free rate of return assures that $P_{t}=V_{t}$. Originally, the latter point derives from the property that the limited supply of risk-free assets pulls together the equilibrium price and the fundamental value, implying that $P_{t} \neq V_{t}$ is impossible regardless of the investors' behavior. In our model, the central bank intervenes the market by controlling the supply of riskfree assets thus setting the risk-free rate.

\section{THE MODEL}

The model follows llomäki (2016) with the extension of a time-varying real risk-free rate of return. The real rate is corrected for inflation so that where the gross inflation is determined as

$$
1+\pi_{t} \equiv \frac{p_{t}}{p_{t-1}}
$$

where $p$ is the general price level in the economy. The economy consists of an infinite set of rational constant absolute risk-averse (CARA) investors, who have asymmetric information so that $0<\mu<1$ of them are informed, and $1-\mu$ of them are uninformed in every period. The atomistic investors live for two periods, investing in the first period, and consuming in the second period.

There is an infinitely lived risky asset (share of firm F), and a risk-free alternative with time-varying real risk-free rate of return $r_{t}^{f}$. The investors allocate their investments between risk-free and risky assets. The portfolio choice is simplified, because the assumption of two-period lived CARA investors omits the possibility of hedging against changes in expected returns, and because the assumption of an infinitely lived risky asset constitutes limits for arbitrage in the overlapping generations model (Shleifer and Vishny, 1997). In addition, assuming normally distributed excess consumption, CARA investors assure that the conditional variance in excess returns is constant.

There are four types of rational investors in every period $t$ : young informed and uninformed investors who open their positions (the demand side), and old informed and uninformed investors who close their positions (the supply side). For simplicity, excess returns are normally distributed, the time-varying risk premium is common to all investors, and there are neither transaction costs nor taxes. The budget constraint comes from the assumption that all young investors at time $t$ have the same individual endowment $w_{t}^{y}$.

The natural logarithm of the dividend $D_{t}$ on firm F's stock follows random walk so that

$\ln D_{t}=\ln D_{t-1}+e_{t}^{d}$, 
where $e_{t}^{d} \sim W N\left(0, \sigma_{d}^{2}\right)$. This means that the change in the dividend at $t$ is permanent. In period $t$, the dividends are paid to old investors.

In period $t$, information common to all informed and uninformed investors consists of the history of equilibrium real prices $\left(\ldots P_{t-3}, P_{t-2}, P_{t-1}\right)$, and the current value of the time varying real risk-free rate $\left(r_{t}^{f}\right)$. Moreover, all investors observe current real dividends $\left(D_{t}\right)$, but the young informed investors have also private information on $D_{t+1}$.

Assume that, in any period $t$, the central bank acts as a social planner with the aim to stabilize the financial markets by adjusting the real risk-free rate of return. The central bank may have perfect or imperfect information on the financial market. In any case, the current value of the real risk-free rate of return $r_{t}^{f}$ is determined by the adjustment to possible mispricing so that it is constant with zero variance from period $t$ to period $t+1$. Supposing that the supply of the risk-free asset is in sole control of the central bank, the market clearing condition for the risk-free asset reads

$$
\int_{y} a_{y}-\int_{c b} b_{c b}=0
$$

where $a_{y}$ is the total demand by the young investors, and $b_{c b}$ is the total supply by the central bank in every period.

Furthermore, assume exogenous noise traders with the distribution $e_{t}^{n t} \sim N\left(0, \sigma_{n t}^{2}\right)$ in the stock market. Thus, the market clearing condition for the risky asset reads

$$
\int_{y} x_{y}-\int_{o} s_{o}+e_{t}^{n t}=0
$$

where $x_{y}$ refers to total demand of the stock by the young investors, and $s_{0}$ is the total supply of the stock by the old investors. The optimal demand decisions produce the equilibrium price in period $t$ thus fulfilling the market clearing condition. This happens because the old investors have to close their position to consume in the second period.

Rational investors care also about the risk of the investment. LeRoy (1973) shows that if the risk-free rate of return is time-varying, and if all investors are risk averse, the proper discount rate includes the risk-free rate and a risk premium. Starting from Markowitz (1952) and Sharpe (1964), risk is defined as the variance of returns.
A rational young investor maximizes individual utility by allocating the initial endowment between risky and risk-free assets. The maximization problem reads

$$
\begin{aligned}
& \operatorname{Max}\left[E\left(-e^{-v c_{t+1}} \mid \theta_{t}^{y}, w_{t}^{y}\right)\right] \\
& \text { s.t. } \\
& c_{t+1}=x^{f}\left(1+r_{t}^{f}\right)+x^{r} E_{t}\left(R_{t+1}\right) \\
& w_{t}^{y}=x^{f}+x^{r},
\end{aligned}
$$

where $\theta_{t}^{y}$ is the information set, $v>0$ is the coefficient of risk aversion, $c_{t+1}$ is consumption when old, $w_{t}^{y}$ is the endowment, and $x^{f}$ and $x^{r}$ denote the amount of money invested in risk-free and risky assets, respectively. The net excess return on a risky share is

$$
R_{t+1} \equiv \frac{P_{t+1}-P_{t}+D_{t+1}}{P_{t}}-r^{f} .
$$

Assuming normally distributed extra consumption, and plugging the consumption constraint into the utility function yields

$$
E_{t}\left[U\left(c_{t+1}\right)\right]=-e^{-v x^{r} E_{t}\left(R_{t+1}\right)+\frac{v^{2}}{2} x^{r^{2}} \sigma_{r}^{2}},
$$

where $\sigma_{r}^{2}$ is the constant variance of excess returns. Note that, since the investors observe $r_{t}^{f}$, its variance is zero. Maximize (7) with respect to $x^{r}$, and use equation (6) to write the first order pricing condition for the risky asset,

$$
P_{t}=\frac{P_{t+1}+D_{t+1}}{1+r_{t}^{f}+x_{t}^{r} v \sigma_{r}^{2}}
$$

Manipulation of (8) results in the optimal investment decision, saying that the stock demand of a rational young investor reads

$$
x_{t}^{r}=\frac{\left(P_{t+1}+D_{t+1}\right) / P_{t}-\left(1+r_{t}^{f}\right)}{v \sigma_{r}^{2}} .
$$

In equation (8), the required net real rate of return is $r_{t}^{n}=r_{t}^{f}+x_{t}^{r} v \sigma_{r}^{2}$, where

$$
x_{t}^{r} v \sigma_{r}^{2}=\frac{P_{t+1}+D_{t+1}}{P_{t}}-\left(1+r_{t}^{f}\right)=\omega_{t}
$$

denotes the time-varying risk premium. In any period $t$, the investors know it upon the choice of $x_{t}^{r}$.

\section{THE FINANCIAL MARKET EQUILIBRIUM}

In the model, all informed investors have the best possible information, and old/young investors 
recognize that young/old investors observe this. Recalling that the properties of random walk say that the change in the dividend at time $t$ is permanent, the rational choice represented by equation (8) results over time in the perpetuity model,

$$
P_{t}=\frac{D_{t+1}}{r_{t}^{n}}=V_{t}
$$

where $r_{t}^{n}=r_{t}^{f}+x_{t}^{i r} v \sigma_{r}^{2}$, in which $x^{i r}$ is the stock demand of an informed investor. Therefore, it can be concluded that equation (11) reflects the fundamental value of the risky asset, and that the informed investors follow the Samuelsonian pricing pattern, $P_{t}^{i}=V_{t}$.

The uninformed investors observe the current real dividend $D_{t}$. Hence, the rational pricing rule for the uninformed investors is

$P_{t}=\frac{D_{t}}{r_{t}^{n}}$

where $r_{t}^{n}=r_{t}^{f}+x_{t}^{u r} v \sigma_{r}^{2}$, in which $x^{u r}$ is the stock demand of an uninformed investor. Using equations (11) and (12), and recalling that $\mu$ is the share of the informed investors, and $1-\mu$ is the share of the uninformed investors, and $i$ denotes informed and $u$ denotes uninformed investors, the aggregate pricing rule in the financial market reads

$$
P_{t}=\mu \frac{D_{t+1}}{r_{t}^{f}+\omega_{t}^{i}}+(1-\mu) \frac{D_{t}}{r_{t}^{f}+\omega_{t}^{u}}
$$

The market price given by equation (13) results from the asymmetry of information among the investors.

Proposition 1: If the risk-free rate of return rises/falls, the investors' attraction to risky investments diminishes/increases.

Proof: Differentiation of equations (11) and (12) against $x_{t}^{i r}\left(x_{t}^{u r}\right)$ and $r_{t}^{f}$ yields

$\frac{\partial x_{t}^{i r}}{\partial r_{t}^{f}}=\frac{\partial x_{t}^{u r}}{\partial r_{t}^{f}}=-\frac{1}{v \sigma_{r}^{2}}<0$,

showing that an increase in the risk-free rate reduces risky investments of both informed and uninformed investors. Q.E.D.

Corollary 1: If the risk-free rate rises/falls, the market price falls/rises, ceteris paribus.

Proof: Differentiate Equation (13) against $P_{t}$ and $r_{t}^{f}$, manipulate, and get $\frac{\partial P_{t}}{\partial r_{t}^{f}}=-\mu \frac{D_{t+1}}{\left(r_{t}^{f}+\omega_{t}^{i}\right)^{2}}-(1-\mu) \frac{D_{t}}{\left(r_{t}^{f}+\omega_{t}^{u}\right)^{2}}<0$,

which shows that a rise/fall of the risk-free rate makes the market price of the stock fall/rise. Q.E.D.

Consider an alternative case, where the uninformed investors operate as technical traders saying that they use past prices to estimate the fair price of today. Manipulating Equation (8), and taking one step backwards yields $P_{t}^{u}=\left(1+r_{t-1}^{f}+\omega_{t-1}^{u}\right) P_{t-1}-D_{t}$, which reduces to

$P_{t}^{u}=\left(1+r_{t}^{f}+\omega_{t}^{u}\right) P_{t-1}-D_{t}$

since $r_{t-1}^{f}=r_{t}^{f}$ because the real risk-free rate remains unaltered unless the central bank interferes, and $\omega_{t-1}^{u}=x_{t-1}^{u r} v \sigma_{r}^{2}=x_{t}^{u r} v \partial_{r}^{2}=\omega_{t}^{u} \quad$ because the uninformed investor makes the investment decision upon past prices. Differentiation of Equation (16) against $x_{t}^{u r}$ and $r_{t}^{f}$ yields again

$\frac{\partial x_{t}^{u r}}{\partial r_{t}^{f}}=-\frac{1}{v \sigma_{r}^{2}}<0$

showing that a rise/fall in the risk-free rate makes investments in the risky asset fall/rise also for technical traders.

By Equations (11) and (16), the aggregate pricing rule in the financial market reads

$P_{t}=\mu V_{t}+(1-\mu)\left[\left(1+r_{t}^{f}+\omega_{t}\right) P_{t-1}-D_{t}\right]$.

Corollary 2: If the risk-free rate rises/falls, the market price falls/rises, ceteris paribus.

Proof: Recall Equation (11), differentiate Equation (16) against $P_{t}$ and $r_{t}^{f}$, and get

$\frac{\partial P_{t}}{\partial r_{t}^{f}}=-\mu \frac{D_{t+1}}{\left(r_{t}^{f}+\omega_{t}\right)^{2}}+(1-\mu) P_{t-1}$.

The effect is negative if $\frac{\mu D_{t+1}}{(1-\mu) P_{t-1}}>\left(r_{t}^{f}+\omega_{t}\right)^{2}$. That is the equilibrium price falls, if the weighted dividend return is larger than squared net required return, which is a reasonable assumption. Q.E.D.

\section{THE CENTRAL BANK}

The market price equations (13) and (17) imply a possibility for a bubble, and the task of the central bank is to avoid such bubbles by manipulating the real risk- 
free rate of return in order to cause desired market reactions described by equations (15) and (18). If the central bank possesses perfect information about the stock market and thus on bubbles, it is able to calculate the market stabilizing real risk-free rate from Equation (13) as follows:

$r_{t}^{f}=\mu \frac{D_{t+1}}{P_{t}}+(1-\mu) \frac{D_{t}}{P_{t}}-\omega_{t}$.

Consider also the case that the central bank does not possess perfect information about the market and bubbles. Assume that the central bank has the same imperfect information as the uniformed investors, knowing only $D_{t}$, and anticipating that $P_{t}=P_{t-1}$ and $D_{t+1}=D_{t}$. Thus, Equation (19) reads

$r_{t}^{f^{\prime}}=\mu \frac{D_{t}}{P_{t-1}}+(1-\mu) \frac{D_{t}}{P_{t-1}}-\omega_{t}$.

Proposition 2 The central bank should intervene in the stock market even if it does not have private information about it.

Proof: Subtract Equation (20) from Equation (19), and write

$r_{t}^{f}-r_{t}^{f^{\prime}}=\mu\left(\frac{D_{t+1}}{P_{t}}-\frac{D_{t}}{P_{t-1}}\right)$.

By Equation (21), the difference of the real risk-free rates that are set with perfect and imperfect information equals the weighted difference between the real dividend yield at period $t+1$ and the real dividend yield at period $t$. The left-hand side of Equation (21) is stationary, if the right-hand side is stationary. Recall Equation (2), $\quad \ln D_{t}=\ln D_{t-1}+e_{t}^{d}$. Hence, both components in the parenthesis on the right-hand side are stationary in Equation (21). The stationarity of the difference between the two real risk-free rates implies that Proposition 1 and Corollaries 1-2 apply also if the central bank possesses imperfect information on the stock market. Q.E.D.

\section{CONCLUSIONS}

The paper presents an overlapping generations model of rational investors with asymmetric information. The overlapping generations model is interpreted so that the wealth managers control people's money, monitored in short-term intervals. The central bank, as a social planner, aims to dampen possible mispricing in the stock market by adjusting the real risk-free rate of return. The active role of the central bank is justified because uninformed investors make mistakes on pricing. By preventing bubbles to inflate the central bank avoids social losses caused by the development and eventual bursting of a super bubble.

The analysis shows that the central bank responds to a marginal emergence of a positive bubble by using its available means to manipulate the real risk-free rate upwards thus reallocating the investments of investors from risky to risk-free assets. Likewise, a negative bubble is dampened by making the real risk-free rate fall thus directing investments from risk-free to risky assets. Thus, the policy adjustment of the real risk-free rate of return levels out any bubbles. Most, importantly, the method is effective even if the central bank has no private information about bubbles.

The results of the paper are worth highlighting, because there does not exist a full consensus neither among academics nor among practitioners about the proper way to intervene in market bubbles. One key issue concerns the validity of the "leaning against the wind" policy. Ours results clearly justify the policy. To be more specific, a positive bubble must be tackled by raising the risk-free rate, and vice versa.

Another important question is whether the central bank should have perfect information about the bubble. Our results simply show that, if the logarithm of dividends follows random walk, then even an interference based on delayed information is sufficient to prevent the developing of the wedge between the fundamental value and the equilibrium price in the stock markets. This happens because the difference of sequential dividend yields is stationary so that the equilibrium price follows a stochastic trend in the fundamental value.

\section{REFERENCES}

Allen, Frank, Stephen Morris and Hyun Shin. 2006. "Beauty Contests and Iterated Expectations in Asset Markets". Review of Financial Studies 19:(7)19-752. https://doi.org/10.1093/rfs/hhj036

Bacchetta, Philippe and Eric Van Wincoop. 2008. "Higher Order Expectations in Asset Pricing". Journal of Money, Credit and Banking 40:(5) 837-866. https://doi.org/10.1111/j.1538-4616.2008.00139.x

Bean, Charles. 2004. "Asset Prices, Financial Instability, and Monetary Policy". American Economic Review 94:(2) 14-18. https://doi.org/10.1257/0002828041301795

Bernanke, Ben and Mark Gertler. 2001. "Should Central Banks Respond to Movements in Asset Prices". American Economic Review 91:(2) 253-257.

Bordo, Michael and Olivier Jeanne. 2002. "Boom-Busts in Assets, Economic Instability, and Monetary Policy". NBER Working Paper No. 8966. 
Campbell, John and Albert Kyle. 1993. "Smart Money, Noise Trading and Stock Price Behavior". Review of Economic Studies 60 (1):1-34. https://doi.org/10.2307/2297810

Cespa, Giovanni and Xavier Vives. 2015. "The Beauty Contest and Short-Term Trading". Journal of Finance 70 (5):2099-2153. https://doi.org/10.1111/jofi.12279

Conlon, John. 2015. "Should Central Banks Burst Bubbles? Some Microeconomic Issues". Economic Journal 125 (582):141161.

https://doi.org/10.1111/ecoj.12154

DeLong, Bradford, Andrei Shleifer, Lawrence Summers and Robert Waldmann. 1990. "Positive Feedback Investment Strategies and Destabilizing Rational Speculation". Journal of Finance, 45 (2):379-395. https://doi.org/10.1111/j.1540-6261.1990.tb03695.x

Fischer, Stanley. 2016. "Monetary Policy, Financial Stability, and the Zero Lower Bound". American Economic Review 106 (5):3942. https://doi.org/10.1257/aer.p20161005

Froot, Kenneth, David Scharfstein and Jeremy Stein. 1992. "Herd on the Street: Informational Inefficiencies in a Market with ShortTerm Speculation". Journal of Finance 47 (4):1461-1484. https://doi.org/10.1111/j.1540-6261.1992.tb04665.x

Gali, Jordi. 2014. "Monetary Policy and Rational Asset Price Bubbles". American Economic Review 104 (3):721-752. https://doi.org/10.1257/aer.104.3.721

Gilenko, Evgenii. (2017). "The "Sudden" Transition to the Free Floating Exchange Rate Regime in Russia in 2014". Journal of Reviews on Global Economics 6 181-192. https://doi.org/10.6000/1929-7092.2017.06.16

Greenspan, Alan. 2004. "Risk and Uncertainty in Monetary Policy". American Economic Review 94 (2):33-40. https://doi.org/10.1257/0002828041301551

llomäki, Jukka. 2016. "Risk-Free Rates and Animal Spirits in Financial Markets". Annals of Financial Economics, 11 (3):118.

https://doi.org/10.1142/S2010495216500111

Kyle, Albert and Wei Xiong. 2001. "Contagion as a Wealth Effect". Journal of Finance 56 (4):1401-1440. https://doi.org/10.1111/0022-1082.00373

LeRoy, Stephen. 1973. "Risk Aversion and the Martingale Property of Stock Prices". International Economic Review 14 (2): 436446.

https://doi.org/10.2307/2525932
Loewenstein, Mark and Gregory Willard. 2006. "The Limits of Investor Behavior". Journal of Finance 61 (1):231-258. https://doi.org/10.1111/j.1540-6261.2006.00835.x

Maio, Paolo. 2014. "Don't Fight the Fed!" Review of Finance 18 (2):623 - 679. https://doi.org/10.1093/rof/rft005

Markowitz, Harry. 1952. "Portfolio Selection". Journal of Finance 7 (1):77-91. https://doi.org/10.1111/j.1540-6261.1952.tb01525.x

Posen, Adam. 2006. "Why Central Banks Should Not Burst Bubbles'. International Finance 9 (1):109-124. https://doi.org/10.1111/j.1468-2362.2006.00028.x

Roubini, Nouriel. 2006. "Why Central Banks Should Burst Bubbles". International Finance 9 (1):87-107. https://doi.org/10.1111/j.1468-2362.2006.00032.x

Samuelson, Paul. 1973. "Proof that Properly Discounted Present Values of Assets Vibrate Randomly". Bell Journal of Economic Management 4 (2):369-374. https://doi.org/10.2307/3003046

Santos, Manuel and Michael Woodford. 1997. "Rational Asset Pricing Bubbles". Econometrica 65 (1):9-57. https://doi.org/10.2307/2171812

Sharpe, William. 1964. "Capital Asset Prices: a Theory of Market Equilibrium Under Conditions of Risk". Journal of Finance 19 (3):425-442. https://doi.org/10.1111/j.1540-6261.1964.tb02865.x

Shiller, Robert 2014. "Speculative Asset Prices". American Economic Review 104 (6):1486-1517. https://doi.org/10.1257/aer.104.6.1486

Shleifer, Andrei and Robert Vishny. 1997. "The Limits of Arbitrage". Journal of Finance 52 (1):35-55. https://doi.org/10.1111/j.1540-6261.1997.tb03807.x

Tirole, Jean. 1982. "On the Possibility of Speculation Under Rational Expectations". Econometrica, 50 (5):1163-1181. https://doi.org/10.2307/1911868

Tirole, Jean. 1985. "Asset Bubbles and Overlapping Generations". Econometrica 53 (5):1499-1528. https://doi.org/10.2307/1913232

Yellen, Janet. 2010. "Closing Panel Presentation". Journal of Money, Credit and Banking 42 (6):243-248. https://doi.org/10.1111/j.1538-4616.2010.00338.x

DOI: https://doi.org/10.6000/1929-7092.2017.06.43

(c) 2017 Ilomäki and Laurila; Licensee Lifescience Global.

This is an open access article licensed under the terms of the Creative Commons Attribution Non-Commercial License (http://creativecommons.org/licenses/by-nc/3.0/) which permits unrestricted, non-commercial use, distribution and reproduction in any medium, provided the work is properly cited. 